Copyright (C) 2015 by Academic Publishing House Researcher

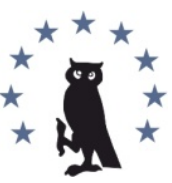

Published in the Russian Federation

European Researcher

Has been issued since 2010.

ISSN 2219-8229

E-ISSN 2224-0136

Vol. 98, Is. 9, pp. 597-603, 2015

DOI: $10.13187 /$ er.2015.98.597

www.erjournal.ru

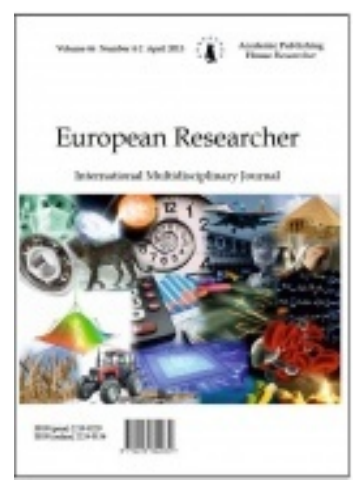

UDC 33

\title{
The Prospects for Industrial Development in the Context of High Natural Gas Prices
}

\author{
Anatolii G. Goncharuk
}

International Humanitarian University, Ukraine

Doctor of Economics, professor

\begin{abstract}
The article presents a study of the source providing a key role in investment activity of the enterprises of metallurgy and chemical industries during a period of high natural gas prices. Based on the results of the study there suggested public policies aimed at revitalizing its work, giving prospects of industrial development.

Keywords: industrial development, pricing, the price of natural gas, investments, investments in fixed assets, the economic crisis.

\section{Введение}

Одним из наиболее весомых факторов последнего десятилетия, оказывающих значительное влияние на промышленное развитие Украины, наряду с финансовоэкономическим кризисом и политической нестабильностью, была и остается высокая цена на природный газ. За период 2005-2013 гг. ее уровень для промышленных потребителей в национальной валюте вырос в 10 раз, а в долларовом эквиваленте в 6,5 раз.

Наиболее зависимыми от природного газа в промышленности страны являются:

металлургия, в которой он используется как энергоресурс в технологических целях;

химическая промышленность, в которой природный газ является ключевым сырьем для производства продукции.

Наши предыдущие исследования (Goncharuk, 2012) показали, что в период финансового кризиса главным источником выживания становится внутренний потенциал предприятия, основанный на качественном менеджменте, эффективном маркетинге и умелом инвестировании, дающим шансы на перспективное развитие бизнеса. Однако в условиях стремительного удорожания основных материальных ресурсов процесс инвестирования может лишиться своих основных источников, к которым относятся:

1) прибыль предприятия;

2) амортизационные отчисления;

3) взносы собственников предприятия;

4) долгосрочные кредиты банков.
\end{abstract}

Цели исследования. Какие источники играют ключевую роль в инвестиционной деятельности предприятий металлургии и химической промышленности в период высокой цены на природный газ? Что может сделать государство для активизации этой 
деятельности, дающей перспективы промышленного развития? Поиску ответов на эти вопросы было посвящено данное исследование.

\section{Материалы и методы}

Природный газ является одним из самых важных энергетических ресурсов в мире. Рынок природного газа имеет свою специфику.

Существует ряд исследований рынка природного газа Европейского Союза (ЕС). Например, Seljom and Rosenberg (2011) устанавливают роль природного газа в импорта энергоресурсов EC. Doukas et al. (2013) анализируют перспективы и проблемы сотрудничества в области природного газа между ЕС и арабскими государствами.

Другие ученые исследуют системы или рынки распределения природного газа в отдельных странах, таких как Турция (Erdogdu, 2010), Италии (Fiorini and Sileo, 2013), Украина (Goncharuk, 2013a), или регионах (Khatib, 2014).

Ряд исследований связан с оценкой факторов, определяющих цену природного газа в некоторых странах (Arano and Velikova, 2012; Slabá et al., 2013), или последствия роста этих цен (Goncharuk, 2013b). Довольно много публикаций оценки эффективности газораспределительных систем в разных странах (Goncharuk, 2008).

Существует также ряд публикаций, посвященных влиянию высоких цен природного газа на деятельность промышленных производителей.

Так, Huang (2007), исследуя американский рынок, подчеркивает, что природный газ является основным сырьем для производства аммиака. На него приходится до 85 процентов себестоимости производства аммиака. Цены на аммиак и природный газ стали весьма коррелировать после 2000 г. Аммиак является основным входным источником азота для большинства химических удобрений продукты, используемые в сельском хозяйстве. Поэтому, начиная с 2000 г., растущий тренд цен на природный газ привел к значительному изменению в предложении аммиака в США. С 2000 по 2006 год США производство аммиака сократилось на 44 процента, импорт аммиака в итоге вырос на 115 процентов. Кроме того, количество аммиачных заводов сократилось с 40 до 25.

Huang (2009) указывает, что за период с января 1999 по июнь 2008 года цены на природный газ увеличилась более чем на 550 процентов. Это способствовало закрытию предприятий и привело к значительному спаду в химическом промышленности.

Аналогично и в других странах химическое производство удобрений зависит от цен на природный газ, например, в Индонезии (Azis et al., 2014) и африканских странах (Hernandez and Torero, 2013). Zalewski (2014) определяет данную проблему как глобальную.

Металлургическая продукция в меньшей степени, но тоже зависит от природного газа, особенно производство в мартеновских печах (Goncharuk, 2015).

Как показали предыдущие исследования (Goncharuk, 2013a), цены на природный газ напрямую влияют на эффективность производства химических и металлургических предприятий.

Таким образом, высокая цена на газ приводит к убыточности производства многих видов химической и металлургической продукции. Чтобы сократить убытки и увеличить прибыль, необходима модернизация производственного процесса, для которой необходимы значительные инвестиции.

В данном исследовании мы попытались опытным путем установить, какие источники инвестиций используют промышленные производители под давлением высоких цен на природный газ. И как может государство стимулировать инвестиционную деятельность и модернизацию в металлургии и химической промышленности.

\section{Методология}

Для установления влияния цены природного газа на деятельности металлургических и химических компаний, в данном исследовании автор использовал традиционные методы корреляционно-регрессионного статистического анализа, включая метод наименьших квадратов (МНК).

Использовалась следующая методика исследования:

1) анализ структуры инвестиций в основной капитал металлургических компаний по основным источникам; 
2) анализ структуру инвестиций в основной капитал химических предприятий по основным источникам;

3) сопоставление изменений структуры инвестиций наблюдаемых компаний с ценами на природный газ;

4) анализ отраслевых показателей эффективности для промышленных потребителей природного газа в стране;

5) установление количественных отношений и разработка прогнозных моделей с помощью регрессионного анализа;

6) выработки рекомендаций по регулированию цен на природный газ для правительства Украины на основе разработанных моделей.

Ключевые индикаторы для анализа в данном исследовании включают:

в) операционную рентабельность как процентное соотношение операционной прибыли к соответствующим затратам;

б) структура инвестиций в основной капитал, включающая следующие источники: прибыль предприятия; амортизация; вклады собственников предприятия; долгосрочные кредиты.

Данные. Для проведения данного исследования использовались данные из следующих источников информации:

1) ежемесячная статистика цен на природный газ для промышленных потребителей, установленных газораспределительными компаниями в Украине, за период 2006-2013 гг.;

2) годовые отчеты крупных металлургических и химических предприятий в Украине за период 2006-2013 гг.;

3) данные предыдущих исследований автора.

Достоверность информации, используемой подтверждается аудиторскими заключениями и государственными службами (ГССУ и НКРЭУ).

\section{Результаты исследования}

В последнее десятилетие динамика цен на природный газ для украинских промышленных потребителей была неоднородной (рис. 1).

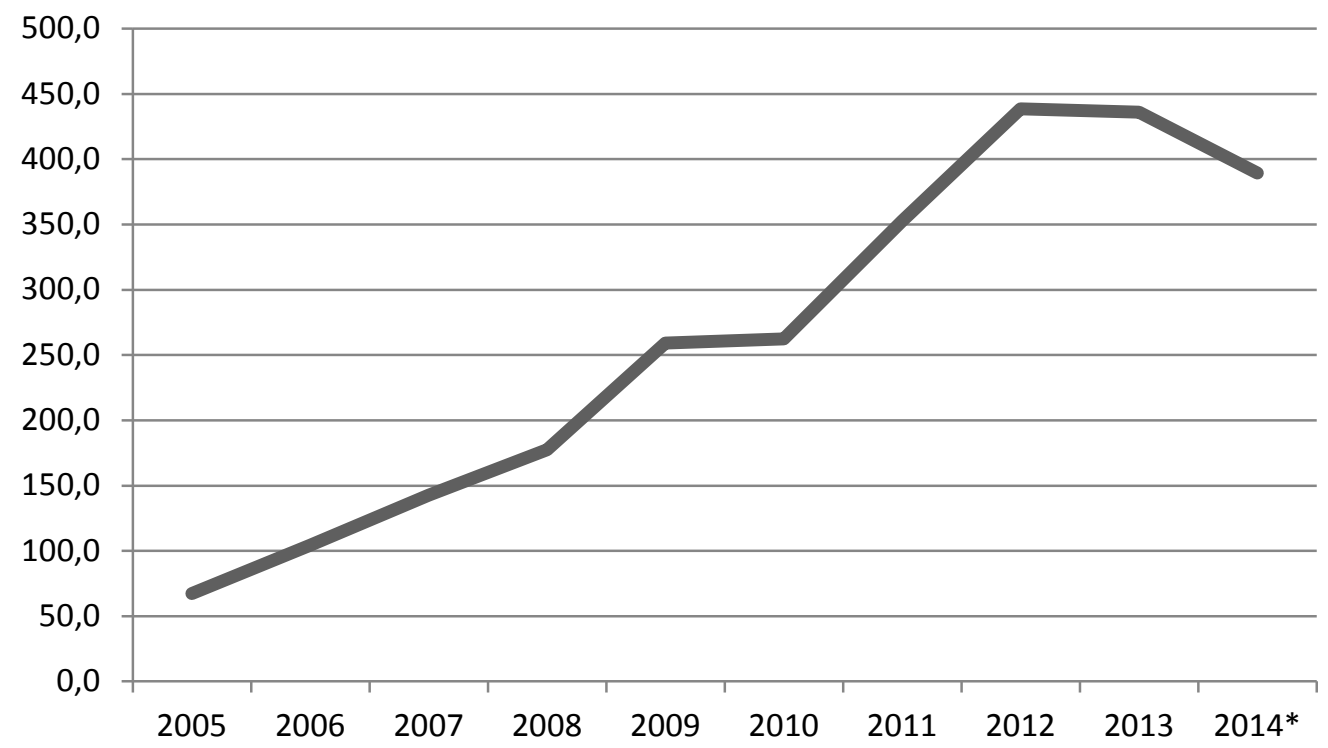

Puc. 1. Динамика средней цены природного газа для промышленных потребителей

Украины, долл. за тыс. куб. м

* - данные за 1 квартал 2014 г.

За исключением периода 2013-2014 гг. газ подорожал. Наибольшие темпы роста были зафиксированы в 2009 г. и 2011-2012 гг. Среднегодовой темп роста за весь период составил 21,5 \%. В целом за десятилетие цены на природный газ в долларовом выражении 
увеличился в 5,8 раза, а в национальной валюте - в 9 раз.

На примере ключевых металлургических и химических предприятий Украины мы исследовали, как изменялась структура инвестиций в основные средства по основным источникам.

По пяти крупнейшим предприятиям металлургии (Азовсталь, Запорожсталь, Арселор Миттал Кривой Рог, Днепровский металлургический комбинат им. Ф.Э. Дзержинского и Мариупольского металлургического комбината им. Ильича), на долю которых приходится более половины всей производимой в стране продукции отрасли, до 2009 г. основным источником формирования инвестиций в основной капитал была прибыль (рис. 1).

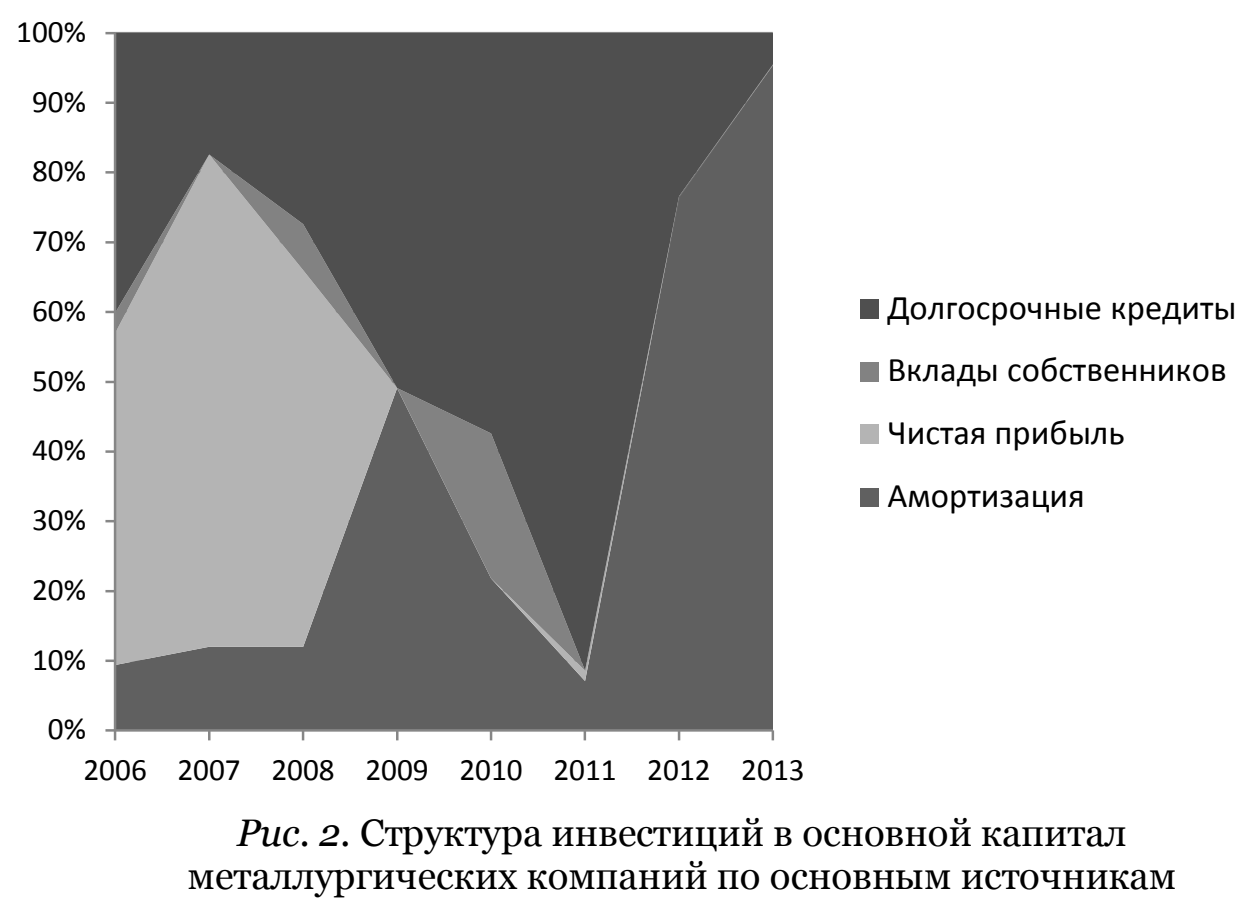

Темпы роста цены на природный газ в период 2006-2008 гг. были относительно не высокими (30-36\% в год). В 2009 г. произошел скачок цены на природный газ в 2,2 раза, который на фоне неблагоприятной конъюнктуры на мировом рынке металлов привел к убыточности отечественной металлургии (Goncharuk, 2013a). В результате объем инвестирования по исследуемым компаниям упал более чем в 2 раза.

К счастью, кризис заставил задуматься многих собственников о переходе производства на другие, менее энергозатратные технологии, и в 2010-2011 гг. инвестиционный процесс в отрасли оживился как за счет вливаний собственников, так и за счет долгосрочных заимствований. Однако дальнейший рост цен на газ привел отрасль в состояние перманентной убыточности, большая часть амортизационных отчислений и кредитов которой уходит на покрытие убытков и лишь остатки направляются на инвестирование в основной капитал. В такой ситуации привлечение кредитов становится затруднительным и амортизационный фонд становится основным источником инвестирования.

Ситуация в химической отрасли выглядит еще более плачевной. Скачок цен на газ в 2009 г. загнал эту отрасль в убытки, из которых она не может выбраться вот уже более 5 лет. Объем инвестиций в данную отрасль, в отличие от металлургии, ежегодно сокращался. Амортизационных отчислений не хватало даже на покрытие убытков и предприятия отрасли накапливали долги по кредитам (рис. 2).

Фактически, нынешний уровень цен на природный газ обрекает химическую промышленность Украины на банкротство. 


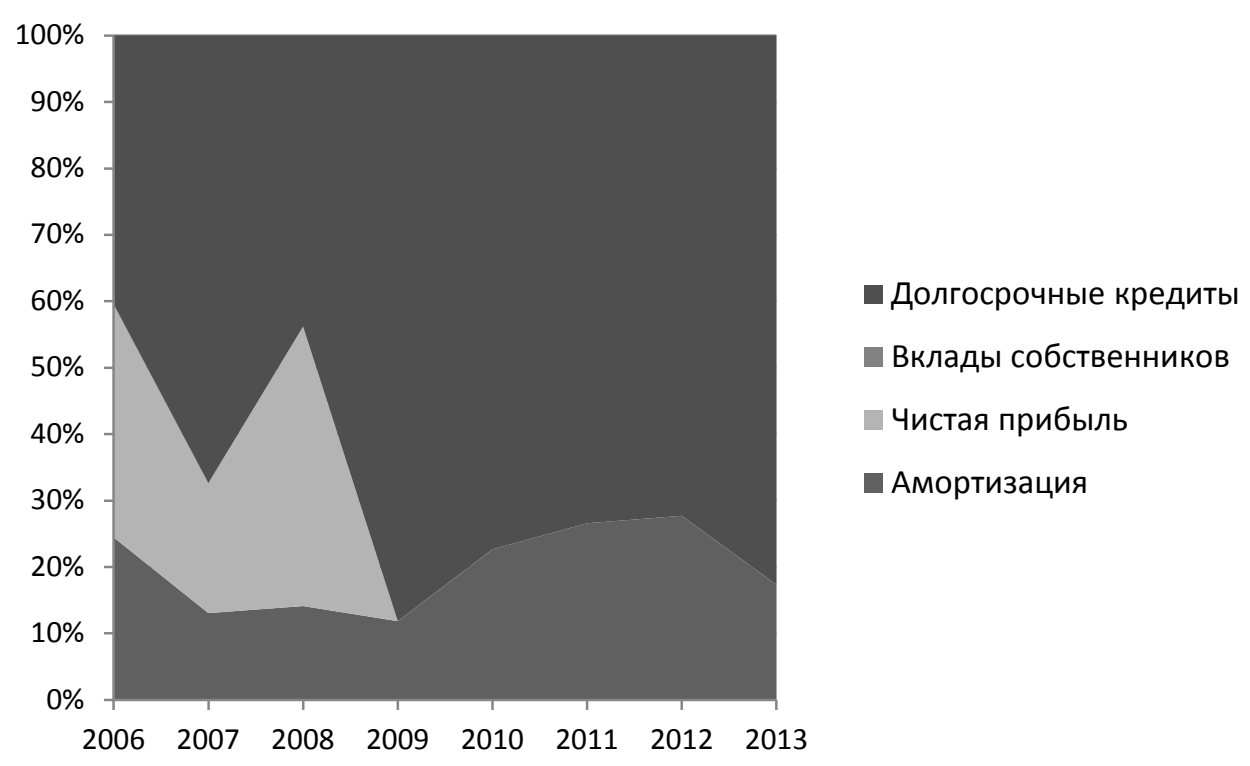

Puc. 3. Структура инвестиций в основной капитал химических компаний по основным источникам

Регрессионный анализ подтвердил ключевую роль цены на природный газ в формировании прибыльности работы предприятий металлургии и химической промышленности. Получены достоверные и адекватные модели, которые можно использовать для прогнозирования среднего уровня рентабельности основных промышленных потребителей природного газа в Украине:

$$
\begin{aligned}
P_{m} & =39.47-0.099 \mathrm{~g},(1) \\
P_{c h} & =45.61-0.136 \mathrm{~g},(2)
\end{aligned}
$$

где $P_{m}$ - рентабельность операционной деятельности предприятий металлургической промышленности Украины, \%;

$P_{c h}$ - рентабельность операционной деятельности предприятий химической промышленности Украины, \%;

g - цена природного газа для промышленных потребителей, долл. США за куб. м.

Как и предполагалось, прибыльность работы химических компаний более чувствительна к изменению цены природного газа:

при нулевой цене на газ она составит более 45 \%, а при росте этой цены на каждые 100 долларов, она будет сокращаться на $13,8 \%$.

Построенные модели позволяют установить критическую цену газа для обеих отраслей, т.е. такую цену, при которой наступает нулевая рентабельность и выше которой отрасль станет убыточной (рис. 4). 


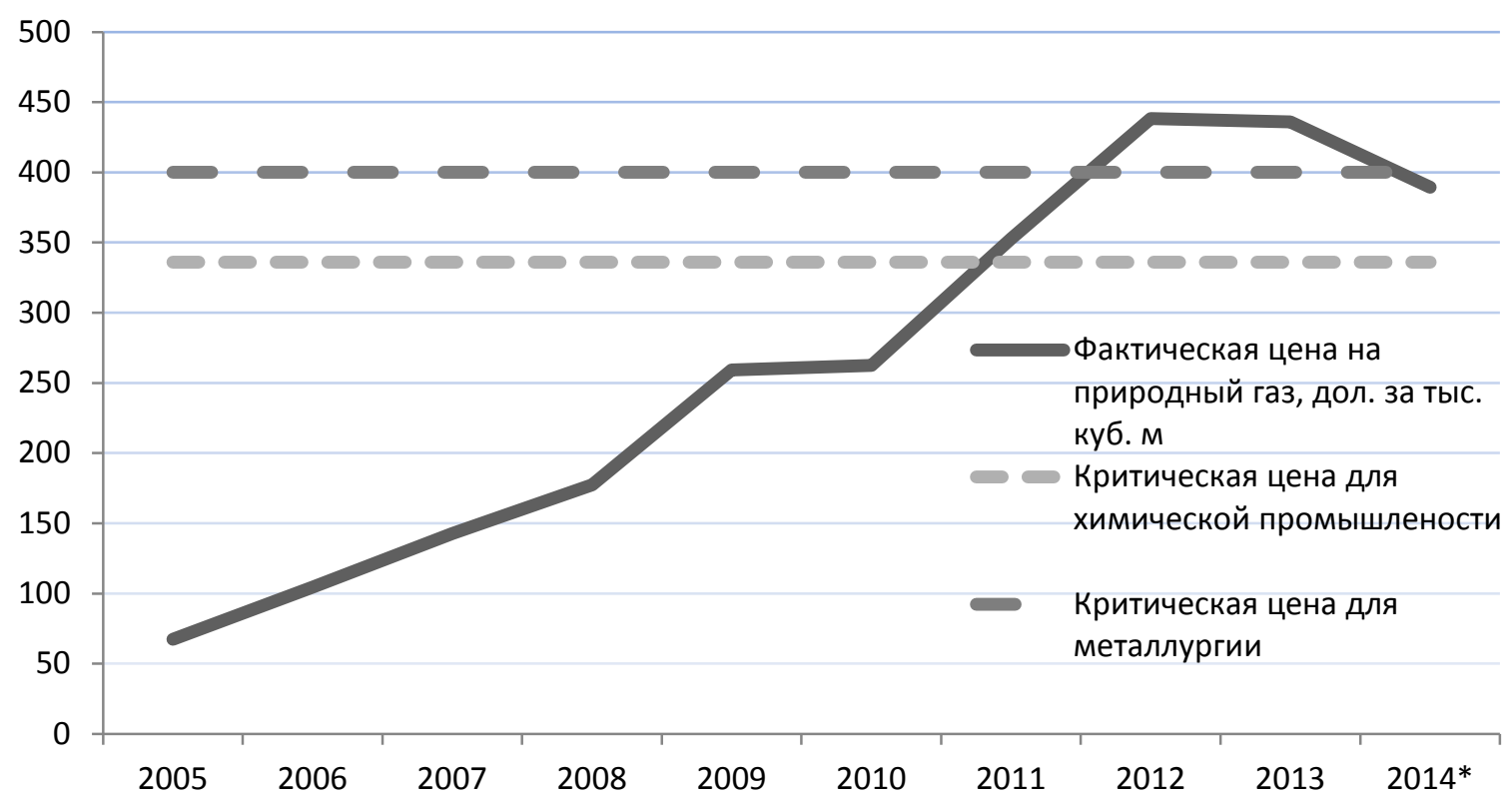

Puc. 4. Критические уровни цены природного газа для металлургии и химической промышленности Украины

Для металлургической промышленности критическая цена на природный газ по состоянию на начало 2014 г. составляет 400 долл. США за тыс. куб. м, для химической - 336 долл. США. Для обеспечения безубыточной работы предприятий данных отраслей государственный регулятор должен удерживать цены на природный газ в данных пределах, в противном случае производство продукции данных отраслей потеряет экономический смысл, что повлечет серьезные потери для всей экономики страны.

В сравнении с ранее полученными критическими уровнями за период до 2013 года (Goncharuk, 2015) уровни на рис. 4 немного снизились. Это указывает на то, что из года в год проблема продолжает углубляться. Необходимы срочные меры для обновления производственных технологий и снижения потребления природного газа. Но с учетом сложной финансово-экономической ситуации в Украине, где фактически идет война, а значит привлечение иностранных и внутренних инвестиций затруднено, на наш взгляд, текущее решение может быть найдено в ценовой дифференциации и государственной поддержке этих отраслей.

Чтобы обеспечить безубыточную деятельность предприятий исследованных отраслей государство должно удерживать цены на природный газ ниже установленных критических уровней. В противном случае работа данных отраслей потеряет экономический смысл, что приведет к серьезным потерям для экономики.

Таким образом, в существующих условиях государственному регулятивному органу (НКРЭУ) целесообразно осуществлять дифференциацию цен на природный газ для различных промышленных потребителей.

\section{Выводы}

В металлургии и химической промышленности Украины стоимость природного газа является ключевым фактором возможности осуществления инвестиционной деятельности предприятий. Превышение цены на газ установленного аналитическим путем критического уровня (для металлургии - 400 долл. США, для химической промышленности - 336 долл. США) приводит данные отрасли в состояние перманентной убыточности, большая часть амортизационных отчислений и кредитов которой уходит на покрытие убытков и лишь остатки направляются на инвестирование в основной капитал.

Для развития промышленного производства в стране необходимы значительные инвестиции в техническое перевооружение и снижение удельного потребления природного газа.

Однако в условиях сохранения существующих технологий для обеспечения развития данных отраслей промышленности экономически целесообразным является осуществление 
дифференциации государственным регуляторным органом цен на природный газ для различных промышленных потребителей в пределах установленных нами критических уровней.

\title{
Примечания:
}

1. Arano, K. and Velikova, M. (2012), "Transportation corridors and cointegration of residential natural gas prices", International J ournal of Energy Sector Management, Vol. 6 (2), pp. 239-254.

2. Azis, G., Siregar, H., Manurung, A. H. and Legowo, E. H. (2014), Gas Re-Allocation Policy on Economic Growth in Indonesia, International Journal of Information Technology and Business Management, Vol. 24 (1), pp. 83-105.

3. Doukas, H., Flamos, A., Marinakis, V. and Assadi, M. (2013), "EU-GCC cooperation for natural gas: prospects and challenges", International J ournal of Energy Sector Management, Vol. 7 (2), pp.194-222.

4. Erdogdu, E. (2010), "A Review of Turkish Natural Gas Distribution Market", Renewable and Sustainable Energy Reviews, Vol. 2(14), pp. 806-813.

5. Fiorini, A. and Sileo, A. (2013), "Infrastructural Equipment and Regulation. Key Interventions for Sustaining Security and Development of the Italian Natural Gas Market", Economics and Policy of Energy and the Environment, Vol. 1, pp. 23-40.

6. Hernandez, M. A. and Torero, M. (2013), Market concentration and pricing behavior in the fertilizer industry: a global approach, Agricultural Economics, Vol. 44(6), pp. 723-734.

7. Huang, W. Y. (2007), Impact of rising natural gas prices on US ammonia supply, DIANE Publishing, Darby, PA.

8. Huang, W. Y. (2009), Factors Contributing to the Recent Increase in U.S. Fertilizer Prices, 200208, DIANE Publishing, Darby, PA.

9. Goncharuk, A. G. (2012), "What Investments Are Most Effective During the Financial Crisis?”, J ournal of Applied Management and Investments, Vol. 1(1), pp. 5-7.

10. Goncharuk, A. G. (2013a), "About the Influence of High Gas Price on an Efficiency", J ournal of Applied Management and Investments, Vol. 2 (1), pp. 58-67.

11. Goncharuk, A. G. (2013b), "What Causes Increase in Gas Prices: The Case of Ukraine", International J ournal of Energy Sector Management, Vol. 7 (4), pp. 448-458.

12. Goncharuk, A. G. (2015), Natural Gas Stakeholders during Price Growth: A Case of Ukraine", International J ournal of Energy Sector Management, Vol. 9 (1), pp. 94-104.

13. Khatib, H. (2014), "Oil and Natural Gas Prospects: Middle East and North Africa", Energy Policy, Vol. 64 (C), pp. 71-77.

14. Seljom, P. and Rosenberg, E. (2011), "A study of oil and natural gas resources and production", International J ournal of Energy Sector Management, Vol. 5 (1), pp. 101-124.

15. Slabá, M., Gapko, P. and Klimešová, A. (2013), "Main Drivers of Natural Gas Prices in the Czech Republic after the Market Liberalisation", Energy Policy, Vol. 52 (C), pp. 199-212.

16. Zalewski, A. (2014), The Global Market for Mineral Fertilizers with Consideration of the Changes in the Prices of Direct Energy Carriers and Raw Materials, Multiannual Program Reports, National Research Institute - Institute of Agricultural and Food Economics - National Research Institute (IAFE-NRI), Warszawa.

удК 33

\section{Перспективы промышленного развития в условиях высоких цен на природный газ}

\author{
Анатолий Георгиевич Гончарук
}

Международный гуманитарный университет, Украина

Доктор экономических наук, профессор

Аннотация. В данной статье проведено исследование источников оказывающих ключевую роль в инвестиционной деятельности предприятий металлургии и химической промышленности в период высокой цены на природный газ. На основе результатов исследования предложены направления государственной политики направленные на активизацию его деятельности, дающей перспективы промышленного развития.

Ключевые слова: промышленное развитие, ценовая политика, цена природного газа, инвестиции, инвестиции в основной капитал, экономический кризис. 